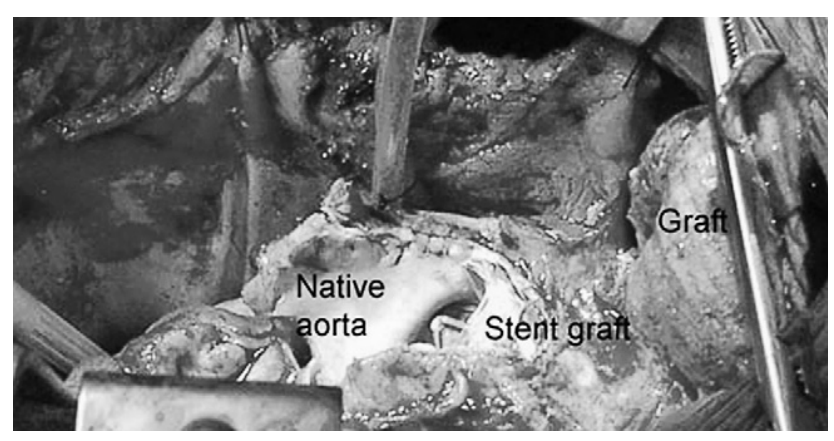

FIGURE 2. Intraoperative photograph showing the exposed portion of the stent graft after detachment of the trifurcated graft.

particularly in the acute setting because outcomes have been poor. Recent approval of thoracic stent grafts has renewed interest in using endoluminal techniques to address these clinical challenges. Endoluminal coverage of the primary tear can reverse malperfusion, promote thrombosis of the false lumen, ${ }^{2}$ and even allow healing and reapproximation of the aortic layers in some cases. ${ }^{3}$ Stent grafting of the dissected aorta can be complicated, however. The acutely dissected aorta is very delicate, and there have been numerous reports of rupture, pseudoaneurysm formation, and retrograde dissection caused by intimal injury or erosion after thoracic endografting. ${ }^{4,5}$ Factors contributing to injury include the acuity of dissection, aortic angulation, device stiffness and design, postimplantation ballooning, and aggressive oversizing.

In aortic dissection tissue friability is the major complicating factor in both open and endovascular repair.
Although we have not encountered this specific complication in the literature, reports of arch transposition in aortic dissections are few in number. Possible mechanisms include injury from wire or device manipulation, strut injury after device deployment, injury from the side-biting clamp, or spontaneous proximal dissection, although this seems less likely. Specific measures to minimize the risk of aortic injury include a gentle endovascular technique, the avoidance of endoaortic ballooning and aggressive oversizing, and the avoidance of proximal and distal landing zones in areas of significant aortic angulation. With regard to arch debranching, it is important to appreciate the propensity that these patients have for aortic dissection. Aggressive control of blood pressure is essential with application of the side-biting clamp, and cardiopulmonary bypass should be considered.

\section{References}

1. Eggebrecht H, Nienaber CA, Newhauser M, Baumgart D, Kische S, Schermund A, et al. Endovascular stent-graft placement in aortic dissection: a meta-analysis. Eur Heart J. 2006;27:489-98.

2. Schoder M, Czerny M, Cejna M, Rand T, Stadler A, Sodeck GH, et al. Endovascular repair of acute type B aortic dissection: long-term follow-up of true and false lumen diameter changes. Ann Thorac Surg. 2007;83:1059-66.

3. Onitsuka S, Akashi H, Tayama K, Okazaki T, Ishihara K, Hiromatsu S, et al. Longterm outcome and prognostic predictors of medically treated acute type B aortic dissections. Ann Thorac Surg. 2004;78:1268-73.

4. Nienaber $\mathrm{C}$, Kishe S, Ince H. Thoracic aortic stent-graft devices: problems, failure modes, and applicability. Semin Vasc Surg. 2007;20:81-9.

5. Svensson L, Kouchoukos N, Miller C, Bavaria J, Coselli J, Curi M, et al. Expert consensus document on the treatment of descending thoracic aortic disease using endovascular stent-grafts. Ann Thorac Surg. 2008;85(suppl): S1-41.

\title{
Ascending aortic arch replacement with aortic valve resuspension under deep hypothermic arrest combined with endoluminal stenting of the descending thoracic aorta and the entire abdominal aorta
}

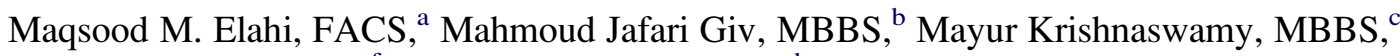 \\ Craig McLachlan, PhD, ${ }^{\mathrm{f}}$ Peter J. Mossop, FRACR, ${ }^{\mathrm{d}}$ and Ian K. Nixon, FRACS, ${ }^{\mathrm{e}}$ \\ Southampton, United Kingdom; and Melbourne and Sydney, Australia
}

\footnotetext{
From the University of Southampton School of Medicine, Southampton General Hospital, ${ }^{a}$ Southampton, United Kingdom; Departments of Vascular Surgery, ${ }^{\mathrm{b}}$ General Surgery, ${ }^{\mathrm{c}}$ Medical Imaging, ${ }^{\mathrm{d}}$ and Cardiothoracic Surgery, ${ }^{\mathrm{e}}$ St Vincent's Hospital, Melbourne, Australia; Department of Medical and Molecular Bio-Sciences, University of Technology, ${ }^{\mathrm{f}}$ Sydney, Australia.

Received for publication June 8, 2008; accepted for publication June 19, 2008; available ahead of print Feb 5, 2009

Address for reprints: Maqsood M. Elahi, FACS, University of Southampton, School of Medicine, Southampton General Hospital, Tremona Rd, Southampton 5016, UK. (E-mail: manzoor_elahi@hotmail.com).

J Thorac Cardiovasc Surg 2009;138:1032-5

$0022-5223 / \$ 36.00$

Copyright (c) 2009 by The American Association for Thoracic Surgery doi:10.1016/j.jtcvs.2008.06.045
}

While the use of hybrid approaches to the treatment of Type-A dissection is growing, the combined use of surgical ascending aortic repair and bare stenting of the residually dissected aorta is relatively novel. In this report we discuss the application of a self-expanding dissection specific bare stent used in combination with surgery for repair of the entire aorta.

\section{CLINICAL SUMMARY}

A 57-year-old man with no previous illnesses presented with type A dissection that extended from the noncoronary 
leaflet of the aortic valve throughout the thoracoabdominal aorta into both common iliac arteries. The intimal flap extended into the innominate, left subclavian, and superior mesenteric arteries with the celiac and left renal arteries arising from the false lumen (Figure 1, A).

Following the induction of anesthesia, the right common femoral was cannulated for the commencement of bypass with a simultaneous median sternotomy. After the aorta was crossclamped, the proximal end was prepared by resuspending the valve and gluing the walls of the aorta back together with BioGlue (CryoLife Inc, Kennesaw, Ga), particularly around the noncoronary cusp. A 30-mm intervascular woven graft was sewn to the proximal cuff, reinforcing the anastomosis with BioGlue. The entry for the aortic dissection was in the anterolateral wall of the arch going just beyond the origin of the left subclavian. The dissected aortic valve, the remaining ascending aorta, and the arch were excised, leaving an island of head and neck vessels and the distal aorta. BioGlue was used to reconstitute the wall, and the graft was fashioned to fit the arch. On completion of rewarming, the patient was weaned uneventfully from bypass with normal ventricular function without inotropes. The first stage of the operation consisted of a total bypass time of 96 minutes and crossclamp time of 50 minutes (Figure 1, B).

After the sternum was closed, the patient was prepared for the placement of the endostents under fluoroscopy and transesophageal echocardiography. A diagnostic catheter was placed in the left common femoral artery, and the right femoral access was used for the stent delivery system. Aortography and transesophageal echocardiography showed that the descending thoracic aorta was intact with no apparent reentries but contained a mobile intimal flap and a moderately large residual false lumen. Reentry tears at the level of the left renal and celiac arteries were observed, with a probable reentry within the right iliac artery. Self-expanding bare metal stents (Zenith Dissection Endovascular Stent, Cook Medical, Bloomington, Ind) were deployed from the straight descending thoracic aorta to just above the aortic bifurcation. Four stent systems were used, ranging in length from 82 to $164 \mathrm{~mm}$ (4-8 stent bodies), all with unconstrained diameters of 46 $\mathrm{mm}$. Significant reexpansion of the true lumen was seen on transesophageal echocardiography after stent implantation with only a small residual false lumen within the thoracic and abdominal aorta. Endovascular procedural time was 45 minutes, and total operating time was 232 minutes. The patient was returned to the intensive care unit in good condition with no inotropic drug administration.

The patient made an excellent recovery without any complications and was discharged on day 10 . The 2 -week postoperative follow-up computed tomographic angiogram scan showed a single lumen thoracoabdominal aorta throughout the treated segments with satisfactory mesenteric and renal artery perfusion (Figure 2).

\section{DISCUSSION}

Acute aortic dissection is a challenging clinical emergency that may have catastrophic consequences if not diagnosed and treated promptly. The incidence is approximately $10-20$ per million per year, ${ }^{1}$ and left untreated, $36 \%$ to $72 \%$ of patients die within 48 hours of diagnosis and $62 \%$ to $91 \%$ or patients die within 1 week. ${ }^{2}$ However, recent technical advances have heralded enormous improvements in its diagnosis and management.

The emergence of endoluminal stent grafting as a treatment strategy $y^{3,4}$ for aortic pathology has significantly altered therapeutic options for complicated aortic dissection. At present, the standard policy in the treatment of acute type A dissection is ascending or total aortic arch repair, and in some cases elephant trunk techniques. Combined endografting of the descending thoracic aorta in combination with open aortic repair has also been reported ${ }^{5,6}$ with encouraging results.

Our rationale for the hybrid approach includes the reconstruction, with minimal additional stress to the patient, of the residually dissected descending and abdominal aorta.
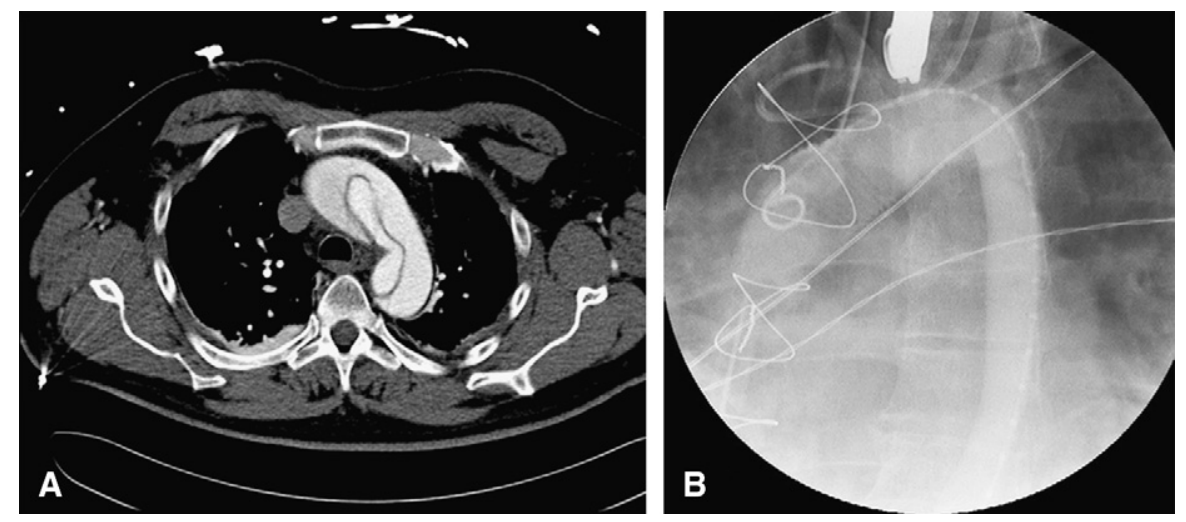

FIGURE 1. A, Multislice computed tomography performed on transfer of the patient to the tertiary referral institution with an initial diagnosis of aortic dissection. B, Arch of the aorta showing the 30-mm intervascular woven graft and great vessels. The dissected aortic, ascending aorta, and arch were excised, leaving an island of head and neck vessels and the distal aorta. The wall was reconstituted, and the graft was fashioned to fit the arch. 


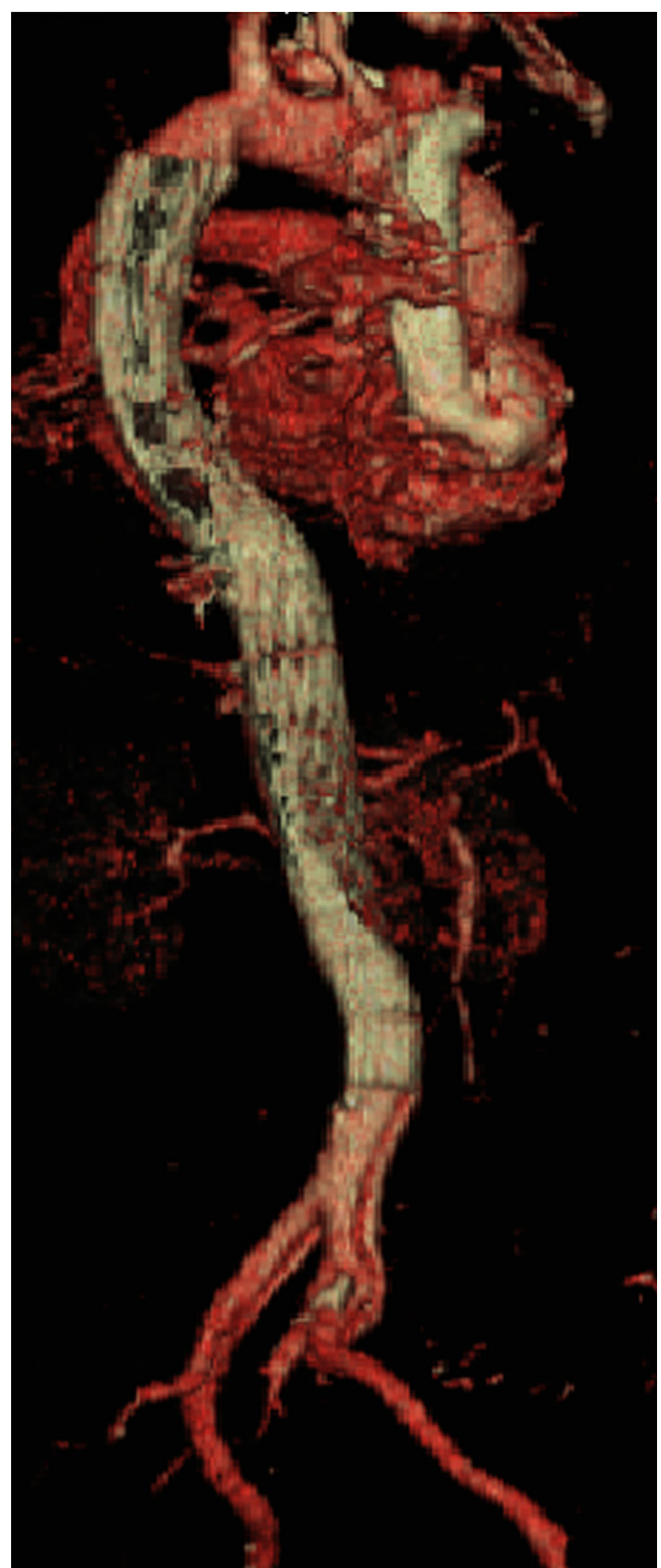

FIGURE 2. Three-dimensional computed tomography angiogram scan 2 weeks after endovascular repair. Obliteration of the false lumen throughout the stented thoracoabdominal aorta with maintenance of all branch vessels is demonstrated.
Stenting also facilitates improved true lumen flow, reverses true lumen collapse, and acts against malperfusion. ${ }^{7-9}$ Similarly, true lumen reexpansion using balloon-expandable stents has also been reported. ${ }^{10}$ Such approaches to malperfusion may render open and endovascular fenestration procedures obsolete.

The dissection-specific bare Z-stent used in this case has also been used in conjunction with endograft closure of residual reentries and branch vessel stenting for total aortic reconstruction, the so-called STABLE technique. ${ }^{11}$ This hybrid approach addresses the problem of persistent false lumen perfusion and the complexity of dissection morphology and aims to achieve a more holistic aortic repair. Such an approach allows reexpansion of the true lumen and initiation of reparative remodeling while the intimal flap is plastic. This potentially allows complete obliteration of the false lumen, as seen in this case. The combined procedure described is a variation of the STABLE technique (previously described for reconstruction of type B dissection), which has not, in our experience, been associated with a greater incidence of procedural difficulties or risk of spinal ischemia. Furthermore, no evidence of stent migration or stent-related intimal trauma has been encountered in our 6-year experience in both acute type A and B dissection. ${ }^{9}$

\section{CONCLUSIONS}

While this more aggressive stent-assisted repair of type A dissection is not a strategy recognized by the majority of surgeons, we suggest that this combined approach is feasible and can be safely performed in selected situations and cases. We now perform hybrid open and endovascular procedures in more than $75 \%$ of patients presenting with type A dissection in whom a significant false lumen or malperfusion exists. False lumen thrombosis or obliteration has been achieved in $85 \%$ of patients, with reparative aortic remodeling seen on follow-up imaging. In none of these cases has there been evidence of progressive aneurysmal dilatation or other remote-phase complication, with survival of $100 \%$ at a mean follow-up of 3 years. ${ }^{9}$

\section{References}

1. Hagan PG, Nienaber CA, Isselbacher EM, Bruckman D, Karavite DJ, Russman PL, et al. The International Registry of Acute Aortic Dissection (IRAD): new insights into an old disease. JAMA. 2000;283:897-903.

2. Nienaber CA, von Kodolitsch Y, Petersen B, Loose R, Helmchen U, Haverich A, et al. Intramural hemorrhage of the thoracic aorta. Diagnostic and therapeutic implications. Circulation. 1995;92:1465-72.

3. Parodi JC, Palmaz JC, Barone HD. Transfemoral intraluminal graft implantation for abdominal aortic aneurysms. Ann Vasc Surg. 1991;5:491-9.

4. Dake MD, Miller DC, Semba CP, Mitchell RS, Walker PJ, Liddell RP. Transluminal placement of endovascular stent-grafts for the treatment of descending thoracic aortic aneurysms. N Engl J Med. 1994;331:1729-34.

5. Liu JC, Zhang JZ, Yang J, Zuo J, Zhang JB, Yu SQ, et al. Combined interventional and surgical treatment for acute aortic type a dissection. Int J Surg. 2008; 6:151-6.

6. Panos A, Kalangos A, Christofilopoulos P, Khatchatourian G. Combined surgical and endovascular treatment of aortic type A dissection. Ann Thorac Surg. 2005; 80:1087-90. 
7. Ito N, Tsunoda $\mathrm{T}$, Nakamura M, Iijima R, Matsuda $\mathrm{K}$, Suzuki $\mathrm{T}$, et al. Percutaneous bare Z-stent implantation as an alternative to surgery for acute aortic dissection with visceral ischemia. Catheter Cardiovasc Interv. 2003;58:101-2.

8. Yamakado K, Takeda K, Nomura Y, Kato N, Hirano T, Matsumura K, et al. Relief of mesenteric ischemia by Z-stent placement into the superior mesenteric artery compressed by the false lumen of an aortic dissection. Cardiovasc Intervent Radiol. 1998;21:66-8

9. Mossop P, Nixon I, Oakes J, Devine TJ, McLachlan CS. Immediate “total" aortic true lumen expansion in type A and B acute aortic dissection after endovascular aortic endografting and GZSD bare stenting. J Thorac Cardiovasc Surg. 2007; 134:1360-2

10. Mossop PJ, McLachlan CS, Amukotuwa SA, Nixon IK. Staged endovascular treatment for complicated type B aortic dissection. Nat Clin Pract Cardiovasc Med. 2005;2:316-21.

11. Léobon B, Roux D, Saccani S, Mugniot A, Muscari F, Glock Y, et al. Type A aortic dissection: new surgical strategy using intra-operative stenting. $J$ Thorac Cardiovasc Surg. 2006;131:482-3.

\title{
Endoprosthetic exclusion of type A aortic dissection through carotid artery
}

\author{
Patrick Ruchat, MD, ${ }^{\mathrm{a}}$ Pierre-Guy Chassot, MD, ${ }^{\mathrm{b}}$ and Elena Rizzo, MD, ${ }^{\mathrm{c}}$ Lausanne, Switzerland
}

Even today, totally endovascular repair of the ascending aorta remains only anecdotally reported, ${ }^{1}$ although $\operatorname{arch}^{2}$ and descending aorta endoprosthetic replacements are currently performed. Recognized treatment of type A dissection still remains emergency replacement of the ascending aorta, with adequate aortic valve and coronary ostial management. ${ }^{3}$ We describe a case in which the surgical strategy had to be somewhat innovative.

\section{CLINICAL SUMMARY}

A 64-year-old white man with a history of subtotal pericardiectomy for constrictive pericarditis had undergone a transseptal mechanical valve replacement 33 years previously to treat a degenerative mitral regurgitation. Because of a severe mediastinal fibrosis, we proceeded through a right anterolateral thoracotomy and right venoarterial femoral cannulation. Because of severe hemodynamic instability during cardiopulmonary bypass, arterial cannulation problems were suspected. Finally, retrograde iatrogenic aortic dissection with involvement of the ascending aorta was confirmed by transesophageal echocardiography. An attempt to replace the ascending aorta was undertaken but discontinued because of the extremely dense, fibrous tissue surrounding all cardiovascular structures. The patient's postoperative course was uneventful, with a computed tomographic (CT) scan confirming an untreated type A dissection without aortic regurgitation and with a reentry tear in the ascending aorta (Figure 1,A). The patient was

\footnotetext{
From the Departments of Cardiovascular Surgery, ${ }^{\mathrm{a}}$ Anesthesiology, ${ }^{\mathrm{b}}$ and Radiology, University Hospital, Lausanne, Switzerland.

Received for publication June 3, 2008; accepted for publication Nov 15, 2008; available ahead of print March 27, 2009.

Address for reprints: Patrick Ruchat, MD, Department of Cardiovascular Surgery, Centre Hospitalier Universitaire Vaudois, Rue du Bugnon 46, CH-1011 Lausanne,

Switzerland (E-mail: Patrick.Ruchat@chuv.ch).

J Thorac Cardiovasc Surg 2009;138:1035-7

$0022-5223 / \$ 36.00$

Copyright (c) 2009 by The American Association for Thoracic Surgery

doi:10.1016/j.jtcvs.2008.11.019
}

discharged on postoperative day 11 with adequate dosages of $\beta$-blocker and angiotensin-converting enzyme inhibitor.

Three months later, control CT scan showed a marked 9-mm increase in the aortic diameter (Figure 1, $B$ and $C$ ). The only option was an endoprosthetic repair of the ascending aorta. After consent had been obtained, a customized $44 \times 70$-mm polytetrafluoroethylene-covered endoprosthesis with distal open web (EndoFit; LeMaitre Vascular, Inc, Burlington, Mass) was inserted through a cutdown to the left common carotid artery, the only nondissected supra-aortic vessel. Good positioning of the endoprosthesis, with confirmation of tear and false-lumen exclusion, was checked by intraoperative transesophageal echocardiography. The postoperative course was clinically uneventful, with the absence of any aortic regurgitation on transthoracic echocardiography. CT scan on postoperative day 2 (Figure 2, A) revealed free coronary ostia and aortic valve commissures, with complete thrombosis of the false lumen an without endoleak. At 1-year follow-up, CT scan showed a complete repair of the aortic wall without compromise on the brachiocephalic trunk at the distal part of the prosthesis (Figure 2, $B$ and $C$ ).

\section{DISCUSSION}

Treatment of iatrogenic type A dissection is emergency replacement of the ascending aorta. ${ }^{4} \mathrm{We}$ had to consider, however, that the only available solution for our threatened patient was an endovascular procedure with remote insertion through the left common carotid artery. ${ }^{5}$ Common carotid clamping is rarely associated with brain ischemia because of collateralization through the external carotid and contralateral facial arteries. In this procedure, we monitored brain ischemia by near-infrared cerebral oximetry with the patient under general anesthesia. This technique is well correlated with clinical neurologic surveillance during carotid endarterectomy with the patient under local anesthesia. Endoprosthesis insertion into the ascending aorta to exclude 